\title{
Gender differences in leisure-time physical activity
}

\author{
Mario Renato Azevedo, Cora Luiza Pavin Araújo, Felipe Fossati Reichert, Fernando Vinholes Siqueira, \\ Marcelo Cozzensa da Silva, Pedro Curi Hallal \\ Post-graduate Program in Epidemiology, Federal University of Pelotas, Brazil
}

Submitted: 27 May 2005; Revisions 17 August, 17 November 2005, 20 April 2006; Accepted: 25 May 2006

Summary

Objectives: To explore the association between gender and leisure-time physical activity in a population-based sample of adults living in Brazil. To study a variety of variables possibly associated with physical activity levels.

Methods: A multistage sampling of households was undertaken in Pelotas, a medium-sized Southern Brazilian city. Leisure-time physical activity was measured using the long version of the International Physical Activity Questionnaire. Data on potential predictors of leisure-time physical activity behavior were collected using a standardized questionnaire. 1344 men and 1756 women were interviewed. Several definitions of moderate and vigorous-intensity physical activity were used.

Results: Regardless of the guideline used, males were more active than women. Socioeconomic level was positively associated with leisure-time physical activity in both genders. A positive dose-response between age and inactivity was found in men, but not among women.

Conclusions: Because men and women have different levels of physical activity, and the variables associated with activity levels are not consistent across the genders, interventions promoting physical activity should take these differences into account.

Keywords: Exercise - Sedentarism - Correlates - Determinants Associated factors - Epidemiology - Developing countries.

The association between physical activity and health is wellknown; active individuals present a lower likelihood of developing several chronic diseases, and exercise is also recommended in the treatment of some diseases (World Health
Organization 2004; U.S Department of Health and Human Services 1996). However, alarming rates of sedentarism are observed both in developed (Varo et al. 2003) and developing countries (Monteiro et al. 2003), in spite of several current initiatives aimed at increasing population activity level (U.S. Department of Health and Human Services 2000; Ministério da Saude 2002). Recently, Bucksch \& Schlicht (2006) reviewed the literature on how much physical activity is enough to prevent detrimental health effects. It was concluded that sedentary men and women can decrease the risk of a whole spectrum of diseases by following current guidelines of 30 minutes of moderate-intensity activities per day on most days of the week (Bucksch \& Schlicht 2006).

Previous studies suggested that males are more active than females in leisure-time, although not all were consistent (Monteiro et al. 2003; Burton \& Turrell 2000; Gomes et al. 2001; Martinez-Gonzalez et al. 2001; Steptoe et al. 2002). More recent data showed that, when all domains of activity practice are considered, no gender differences are observed (Hallal et al. 2003). Few studies, however, have explored the variables associated with physical inactivity among men and women separately, and most of these were carried out in high-income countries, where activity patterns are different from those observed within low and middle-income ones.

The aim of this study was to explore leisure-time physical activity patterns and associated variables among men and women separately in a population-based sample of adults living in Brazil.

\section{Materials and methods}

A cross-sectional health investigation was carried out in Pelotas, a medium-sized (320000 inhabitants) Southern Brazilian city, in the last trimester of 2003. The sample was se- 
lected in multiple-stages. All urban census tracts $(\mathrm{N}=404)$ of Pelotas were stratified by the average income of family heads. Thereafter, 144 were sampled with probability proportionate to the size. Within each selected tract, households were sampled following a systematic protocol, and taking the size of the tract (number of households) into account. All residents of each sampled household were interviewed. These analyses were restricted to individuals aged 20 years or more.

The actual sample size interviewed $(\mathrm{N}=3100)$ enabled us to detect significant differences between males and females in the proportion of compliance with physical activity recommendations as small as two percentage points.

Leisure-time physical activity was assessed using the section four (recreation, sports and leisure-time) of the long version of the International Physical Activity Questionnaire (IPAQ) (Craig et al. 2003). The IPAQ computes only activities performed for at least 10 consecutive minutes. Walking, moderate- and vigorous-intensity activities are assessed; definition of the intensity of each activity is based on the degree of physical effort required, taking changes in respiration rate into account. A physical activity score was constructed as the weekly time spent in moderate-intensity (including walking) plus twice the weekly time spent in vigorous-intensity activities, as suggested previously (Hallal et al. 2003). The score was divided into four groups for some specific analyses: 0 minutes/week: physically inactive; 1-149 minutes/week: some degree of activity, but insufficiently active to obtain health benefits; 150-499 minutes/ week: sufficiently active; $\geq 500$ minutes/week: highly active. This categorization was used in previous publications (Hallal et al. 2005). Validity of the IPAQ was tested in Brazil in several studies (Pardini et al. 2001; Barros \& Nahas 2000; Hallal et al. 2004). Overall, results of these studies indicate the IPAQ is a reliable tool for measuring physical activity in this setting.

The independent variables included were age, economic level (Classification of the National Agency of Research Institutes, which considers both household assets and education of the family head, and where " $\mathrm{A}$ " is the wealthiest group), schooling (years of education), smoking status, and self-reported health status. Among individuals who performed at least 10 minutes of physical activity in the seven days prior to the interview, the main reason for being engaged in physical activity was also investigated. The question used for this purpose was: "Which of the following reasons is the most important in order to make you practice physical activity?" The options were: (a) medical advice; (b) enjoyment; (c) belief that physical activity is important for health; and (d) other reasons (opened-ended alternative).

Women with at least secondary education collected data in face-to-face interviews. They were trained for 40 hours in the application and codification of the questionnaire, and were blinded to the aims of the study. Individuals were only classified as non-respondents when they were not interviewed after at least three contacts of the interviewer (different days and hours) and one of a field supervisor.

The significance level used was 5\%. All analyses took the clustering of the sample into account. Differences between categorical variables were calculated using the chi-square tests for heterogeneity and trend. Differences between means were calculated using the t-test and analysis of variance. Logistic Multinomial regression models were used for adjusted analyses.

The Federal University of Pelotas Medical School Ethical Committee approved the research protocol, and informed consents were obtained from each subject.

\section{Results}

Within the 1530 sampled households, 1407 men and 1807 women eligible for the study were found, of whom 1344 men and 1756 women were actually interviewed. Thus, non-response was $4.5 \%$ among men and $2.8 \%$ among women. Table 1 describes the sample in terms of socio-demographic variables, smoking status and self-reported health status stratified by gender. Females were on average older than males. Schooling and socioeconomic level distributions were similar among men and women. The prevalence of smoking was $35 \%$ higher in men than in women. Men tended to classify their health better than women.

Table 2 describes the sample in terms of several leisure-time physical activity indicators. Days of walking were similarly reported across the sexes, while the practice of moderate and vigorous-intensity physical activities was more frequent among men. The proportion of individuals with score zero was $29 \%$ higher in women than men, and the prevalence of high activity level (score $\geq 500$ ) was two-fold higher among men than among women (10.8\% and $5.4 \%$, respectively). Treating this physical activity score as a continuous variable, the average \pm SD among men was $189 \pm 374$, while among women it was $105 \pm 246$. The $5^{\text {th }}, 25^{\text {th }}, 50^{\text {th }}, 75^{\text {th }}$ and $95^{\text {th }}$ percentiles among men were $0,0,15,240$ and 840, while among women the equivalent values were $0,0,0,120$ and 540. Both distributions were positively skewed $(\mathrm{p}<0.001)$.

Figure 1 shows the percentage of compliance with several interpretations of current physical activity recommendations used in the literature among men and women separately. Men were more likely than women to achieve all criteria, with stronger relative differences for the vigorous activities guidelines (criteria 3 and 4).

Table 3 shows the variables associated with physical activity practice among men and women. Among males, individuals in the intermediate age groups were more likely to score 


\begin{tabular}{|c|c|c|c|}
\hline VARIABLE & MEN $(n=1344)^{a}$ & WOMEN $(n=1756)^{b}$ & $P$ value \\
\hline Mean (SD) age in years & $42.6(15.5)$ & $43.7(16.6)$ & $0.04^{c}$ \\
\hline Age groups (years) & & & $0.22^{\mathrm{d}}$ \\
\hline $20-29$ & $25.5 \%(342)$ & $23.8 \%(417)$ & \\
\hline $30-39$ & $20.8 \%(279)$ & $20.8 \%(366)$ & \\
\hline $40-49$ & $22.5 \%(303)$ & $21.5 \%(377)$ & \\
\hline $50-59$ & $15.9 \%(213)$ & $16.0 \%(280)$ & \\
\hline $60-69$ & $8.8 \%(118)$ & $8.9 \%(157)$ & \\
\hline$\geq 70$ & $6.6 \%(89)$ & $9.1 \%(159)$ & \\
\hline Mean (SD) schooling in years & $7.6(4.3)$ & $7.8(4.5)$ & $0.17^{c}$ \\
\hline Schooling groups (years) & & & $0.05^{\mathrm{d}}$ \\
\hline $0-4$ & $26.0 \%(349)$ & $26.3 \%(462)$ & \\
\hline $5-8$ & $34.9 \%(468)$ & $31.0 \%(545)$ & \\
\hline $9-11$ & $25.9 \%(348)$ & $26.7 \%(468)$ & \\
\hline$\geq 12$ & $13.2 \%(177)$ & $16.0 \%(281)$ & \\
\hline Economic level & & & $0.39^{d}$ \\
\hline A & $5.1 \%(68)$ & $4.6 \%(81)$ & \\
\hline B & $20.9 \%(279)$ & $19.8 \%(347)$ & \\
\hline c & $32.8 \%(438)$ & $33.1 \%(579)$ & \\
\hline D & $34.0 \%(454)$ & $36.5 \%(639)$ & \\
\hline E & $7.2 \%(95)$ & $5.9 \%(103)$ & \\
\hline Smoking status & & & $<0.001^{\mathrm{d}}$ \\
\hline Never smokers & $41.4 \%(556)$ & $58.7 \%(1031)$ & \\
\hline Former smokers & $27.4 \%(368)$ & $18.2 \%(319)$ & \\
\hline Current smokers & $31.2 \%(420)$ & $23.1 \%(406)$ & \\
\hline Self-reported health status & & & $<0.001^{\mathrm{d}}$ \\
\hline Excellent & $15.8 \%(213)$ & $10.4 \%(182)$ & \\
\hline Very good & $17.6 \%(236)$ & $13.3 \%(232)$ & \\
\hline Good & $47.0 \%(631)$ & $46.0 \%(803)$ & \\
\hline Average & $17.0 \%(229)$ & $25.8 \%(450)$ & \\
\hline Poor & $2.6 \%(35)$ & $4.5 \%(79)$ & \\
\hline
\end{tabular}

Table 1 Description of the sample in terms of socio-demographic and behavioral variables stratified by gender

a The maximum number of missing values was 9 (economic level)

${ }^{b}$ The maximum number of missing values was 10 (self-reported health status)

${ }^{\mathrm{c}}$ T-test ${ }^{\mathrm{d}}$ Chi-square test

zero, while among females, older ones ( $\geq 70$ years) were more likely to be sedentary. No dose-response associations were detected between physical activity score and age regardless of the gender. The Spearman correlation coefficient between the continuous physical activity score and age was -0.19 among men and -0.03 among women.

In terms of schooling level, males with $\geq 9$ years of formal education presented $75 \%$ lower risk of scoring zero in comparison to those with low education ( $0-4$ years). Among women, this difference was less extreme (35\%). The Spearman correlation coefficient between the continuous physical activity score and years of formal education was 0.23 among males and 0.18 among females.

Economic level showed a clear dose-response positive associ- ation with the physical activity score among women. Those in the group "E" presented $110 \%$ increased prevalence of score zero in comparison with those from level "A". Among men, groups "C", "D" and "E" presented comparable prevalence of subjects scoring zero, approximately $60 \%$ higher than males from the "A" level.

In both sexes, never smokers presented a lower prevalence of no physical activity (score 0 ). However, the prevalence ratio for having no activity among current smokers in comparison with never smokers was different across the sexes (1.42 among males and 1.15 among females). The worse the selfreported health status, the lower the proportion of subjects with a physical activity score above the 150-minute threshold, both in men and women. 


\begin{tabular}{|c|c|c|}
\hline VARIABLE & $\operatorname{MEN}(n=1344)^{a}$ & WOMEN $(n=1756)$ \\
\hline \multicolumn{3}{|c|}{ Days of walking in the previous week* } \\
\hline 0 & $72.0 \%(968)$ & $70.9 \%(1242)$ \\
\hline $1-2$ & $9.0 \%(121)$ & $9.4 \%(166)$ \\
\hline $3-4$ & $6.9 \%(92)$ & $8.4 \%(148)$ \\
\hline$\geq 5$ & $12.1 \%(162)$ & $11.3 \%(199)$ \\
\hline \multicolumn{3}{|c|}{$\begin{array}{l}\text { Days of moderate activities (other than walking) } \\
\text { in the previous week** }\end{array}$} \\
\hline 0 & $76.0 \%(1020)$ & $92.1 \%(1616)$ \\
\hline $1-2$ & $14.2 \%(191)$ & $3.9 \%(69)$ \\
\hline $3-4$ & $4.8 \%(65)$ & $2.1 \%(37)$ \\
\hline$\geq 5$ & $5.0 \%(67)$ & $1.9 \%(34)$ \\
\hline \multicolumn{3}{|c|}{ Days of vigorous activities in the previous week** } \\
\hline 0 & $81.4 \%(1094)$ & $92.2 \%(1619)$ \\
\hline $1-2$ & $8.5 \%(114)$ & $2.9 \%(50)$ \\
\hline $3-4$ & $5.6 \%(75)$ & $3.2 \%(57)$ \\
\hline$\geq 5$ & $4.5 \%(61)$ & $1.7 \%(29)$ \\
\hline \multicolumn{3}{|c|}{ Leisure-time physical activity score ${ }^{a} * *$} \\
\hline 0 & $49.8 \%(670)$ & $64.4 \%(1126)$ \\
\hline $1-149$ & $17.1 \%(229)$ & $13.6 \%(238)$ \\
\hline $150-499$ & $22.3 \%$ (298) & $16.6 \%(290)$ \\
\hline$\geq 500$ & $10.8 \%(144)$ & $5.4 \%(95)$ \\
\hline
\end{tabular}

* $p=0.25$ (Chi-square test)

** $\mathrm{p}<0.001$ (Chi-square test)

a Minutes/week spent in moderate activities (including walking) + minutes/week of vigorous activities times two

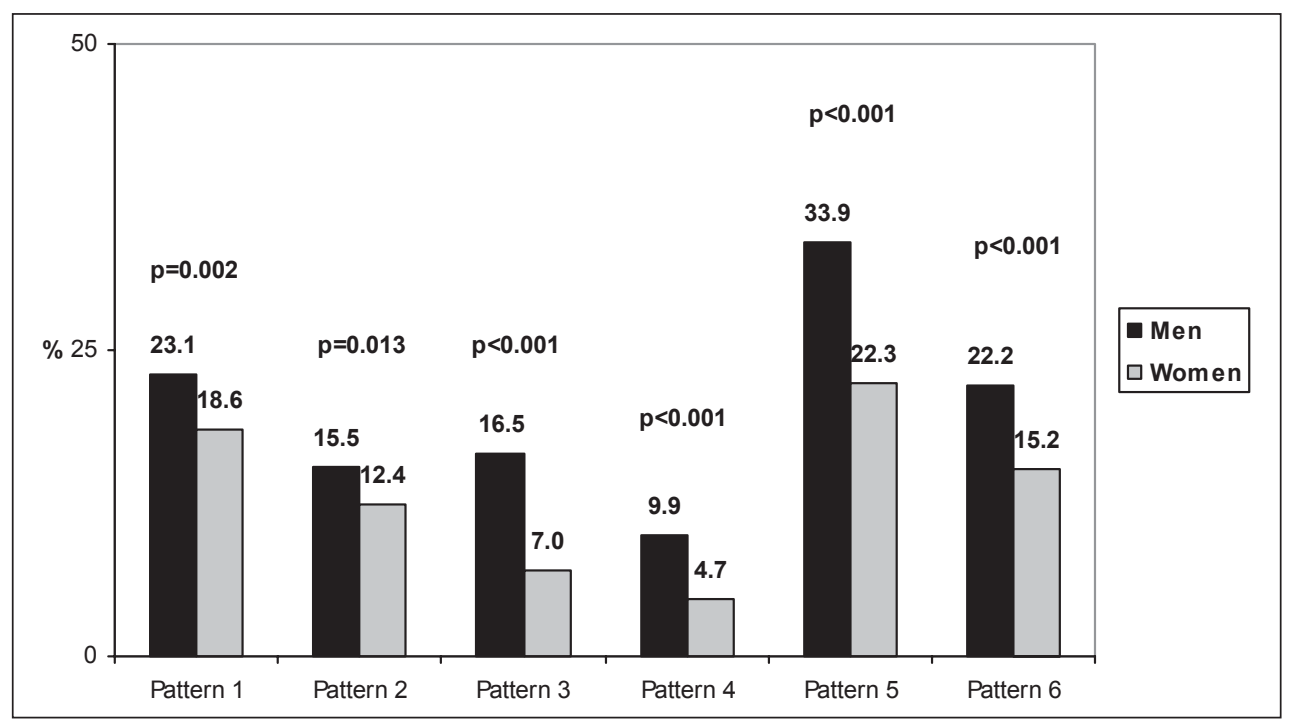

Figure 1 Compliance with different interpretations of current physical activity guidelines among men and women

* p-values were calculated using the Chi-square test

Criteria 1: $\geq 150 \mathrm{~min} / \mathrm{wk}$ of moderate activities (including walking) Criteria 2: $\geq 150 \mathrm{~min} / \mathrm{wk}$ of moderate activities (including walking) performed in at least 5 days Criteria 3: $\geq 60 \mathrm{~min} / \mathrm{wk}$ of vigorous activities

Criteria 4: $\geq 60 \mathrm{~min} / \mathrm{wk}$ of vigorous activities performed in at least 3 days Criteria 5: Compliance with guideline 1 and/or 3

Criteria 6: Compliance with guideline 2 and/or 4

Correlates - Determinants

- Associated factors - Epidemiology

- Developing countries.

All analyses presented in Table 3 were repeated using Multinomial Logistic Regression. The results were consistent with those observed in the crude analysis, and therefore, are not presented. Only one important exception was observed: the effect of smoking (former and current) on the proportion of individuals scoring zero among males was minimized from 1.98 and 2.13, respectively (crude analyses) to 1.46 and 1.54 (after adjusting for age, economic level and schooling).

Among all individuals who reported practicing at least 10 minutes of physical activity in the week prior to the inter- 
Table 3 Description of the sample in terms of leisure-time physical activity variables stratified by gender

\begin{tabular}{|c|c|c|c|c|c|c|c|c|}
\hline \multirow{3}{*}{ VARIABLE } & \multicolumn{2}{|c|}{ MEN $(n=1344)$} & \multicolumn{2}{|c|}{ WOMEN $(n=1756)$} & & & & \\
\hline & Total pl & al activit & & & \multicolumn{4}{|c|}{ Total physical activity score } \\
\hline & 0 & $1-149$ & $\geq 150$ & P value* & 0 & $1-149$ & $\geq 150$ & P value* \\
\hline Age & & & & $<0.001$ & & & & 0.02 \\
\hline $20-29$ & $34.1 \%$ & $17.9 \%$ & $47.9 \%$ & & $59.7 \%$ & $15.7 \%$ & $24.6 \%$ & \\
\hline 30-39 & $50.9 \%$ & $17.6 \%$ & $31.5 \%$ & & $67.5 \%$ & $13.9 \%$ & $18.6 \%$ & \\
\hline $40-49$ & $58.3 \%$ & $18.5 \%$ & $23.2 \%$ & & $66.8 \%$ & $10.1 \%$ & $23.1 \%$ & \\
\hline $50-59$ & $58.7 \%$ & $14.1 \%$ & $27.2 \%$ & & $62.4 \%$ & $12.5 \%$ & $25.1 \%$ & \\
\hline $60-69$ & $55.1 \%$ & $15.3 \%$ & $29.7 \%$ & & $60.0 \%$ & $16.1 \%$ & $23.9 \%$ & \\
\hline$\geq 70$ & $51.7 \%$ & $16.9 \%$ & $31.5 \%$ & & $71.5 \%$ & $15.2 \%$ & $13.3 \%$ & \\
\hline $\begin{array}{l}\text { Schooling level } \\
\text { (years of formal education) }\end{array}$ & & & & $<0.001$ & & & & $<0.001$ \\
\hline $0-4$ & $66.4 \%$ & $12.1 \%$ & $21.6 \%$ & & $73.0 \%$ & $12.6 \%$ & $14.4 \%$ & \\
\hline $5-8$ & $51.1 \%$ & $18.4 \%$ & $30.6 \%$ & & $70.0 \%$ & $11.6 \%$ & $18.4 \%$ & \\
\hline $9-11$ & $39.1 \%$ & $17.8 \%$ & $43.1 \%$ & & $56.8 \%$ & $14.1 \%$ & $29.1 \%$ & \\
\hline$\geq 12$ & $36.2 \%$ & $22.0 \%$ & $41.8 \%$ & & $52.0 \%$ & $18.2 \%$ & $30.0 \%$ & \\
\hline Economic level & & & & $<0.001$ & & & & $<0.001$ \\
\hline A & $33.8 \%$ & $14.7 \%$ & $51.5 \%$ & & $37.0 \%$ & $14.8 \%$ & $48.2 \%$ & \\
\hline B & $40.5 \%$ & $20.1 \%$ & $39.4 \%$ & & $53.5 \%$ & $15.0 \%$ & $31.5 \%$ & \\
\hline C & $55.3 \%$ & $15.5 \%$ & $29.2 \%$ & & $64.9 \%$ & $13.8 \%$ & $21.3 \%$ & \\
\hline D & $52.0 \%$ & $16.5 \%$ & $31.5 \%$ & & $71.2 \%$ & $13.3 \%$ & $15.5 \%$ & \\
\hline $\mathrm{E}$ & $55.8 \%$ & $21.1 \%$ & $23.2 \%$ & & $77.0 \%$ & $9.0 \%$ & $14.0 \%$ & \\
\hline Smoking status & & & & $<0.001$ & & & & 0.005 \\
\hline Never smokers & $40.1 \%$ & $19.4 \%$ & $40.5 \%$ & & $60.8 \%$ & $14.4 \%$ & $24.8 \%$ & \\
\hline Former smokers & $56.5 \%$ & $14.7 \%$ & $28.8 \%$ & & $68.7 \%$ & $11.9 \%$ & $19.4 \%$ & \\
\hline Current smokers & $57.0 \%$ & $16.0 \%$ & $27.0 \%$ & & $70.0 \%$ & $12.8 \%$ & $17.2 \%$ & \\
\hline Self-reported health status & & & & $<0.001$ & & & & $<0.001$ \\
\hline Excellent & $35.7 \%$ & $14.1 \%$ & $50.2 \%$ & & $55.5 \%$ & $12.6 \%$ & $31.9 \%$ & \\
\hline Very good & $42.8 \%$ & $20.3 \%$ & $36.9 \%$ & & $53.0 \%$ & $16.8 \%$ & $30.2 \%$ & \\
\hline Good & $52.2 \%$ & $18.9 \%$ & $28.9 \%$ & & $65.1 \%$ & $13.9 \%$ & $21.0 \%$ & \\
\hline Average/Poor & $62.1 \%$ & $12.1 \%$ & $25.8 \%$ & & $70.7 \%$ & $12.4 \%$ & $16.9 \%$ & \\
\hline
\end{tabular}

* Wald test for heterogeneity

view, the main reason for physical activity practice was investigated. Medical advice was the main reason for physical activity practice among $8.4 \%$ of the men and $18.5 \%$ of the women; enjoyment was reported by $47.9 \%$ of the men and $24.6 \%$ of the women studied. The answer "because physical activity is important for health" was given by $41.2 \%$ of all men and $52.9 \%$ of all women. Other reasons were reported by less than $5 \%$ in both sexes.

\section{Discussion}

In a population-based sample of Brazilian adults, leisure-time physical activity level in males and females was explored. Men presented higher activity levels than women in terms of moderate-intensity, vigorous-intensity and total leisure-time physical activity practice. Walking was the only group of activities similarly reported among males and females. Variables associated with physical activity practice were mostly similar across the sexes, although some important differences were observed. The reasons for physical activity practice were completely different among men and women, a finding that might help explain the different activity levels observed. Our results are in accordance with previous studies, from both developed and developing countries, which showed that men are more active than women in leisure-time (Monteiro et al. 2003; Burton \& Turrell 2000; Gomes et al. 2001; MartinezGonzalez et al. 2001; Steptoe et al. 2002). However, when other domains of activity practice (housework, transporta- 
tion and occupational) are considered, no gender differences are observed (Hallal et al. 2003), except for vigorous activities (Hallal \& Siqueira 2004). This is possibly explained by a higher level of housework physical activity among females. A previous study proposed the term "gender bias" to explain the role of the domains evaluated on the differences in physical activity level across the sexes; in that study, men were more likely to practice sports and exercise, while females were more likely to perform daily walking and biking (Abel et al. 2001). A strong association between socioeconomic level and leisure-time physical activity was found. For both genders, the lower the socioeconomic level, the higher the rate of inactivity. Comparable findings have been found in high-income countries and other Brazilians areas (Varo et al. 2003; Monteiro et al. 2003; Burton \& Turrell 2000; Martinez-Gonzalez et al. 2001; Evenson et al. 2002). An explanation for this finding relies on the lack of appealing public places for physical activity practice. Individuals are, somehow, tempted to search for structured activities (e.g. sports at clubs and gym at fitness clubs), all of which require an investment of money. Moreover, individuals of lower socioeconomic status have less knowledge about exercise-related issues, which may contribute to their negative lifestyle (Domingues et al. 2004). Nonetheless, it is very interesting to note that a previous study, carried out in the same Brazilian city (Hallal et al. 2003), showed that when all-domains of activities are considered, the direction of the association between socioeconomic status and physical activity level is exactly the opposite: the lower the socioeconomic level, the lower the rate of inactivity. We believe that this association might also be observed in other countries, particularly low and middleincome ones, where a considerable amount of activities are performed during work, commuting, and household chores. Another important issue is that individuals of low income are not more likely to be sedentary just because they have less money or less knowledge on physical activity benefits. These subjects also have different attitudes to their own health and body (Marmot 2000).

The association between physical activity and age differed between the sexes. Among men, middle-aged adults were more likely to be sedentary, while among women, older adults were more sedentary. A study in countries of the European Union (Martinez-Gonzalez et al. 2001) demonstrated that men tend to decrease participation in leisure-time physical activities as they get older; whereas this dose-response was not seen among women. Gomez et al. (2004) also found no linearity between age and physical activity level among women. In their study, middle-aged women (30-49 years) presented the higher proportion of inactivity. Further studies are needed to clarify why the association between physical activity and age is gender-dependent. Furthermore, whether this association is also observed when activities practiced in other settings than leisure-time are considered, is an unanswered question.

Despite the fact that this was a cross-sectional investigation, and no causal inference shall be made between smoking status and physical activity level, we explored the cross-sectional association between these variables. Both men and women, who were currently smokers presented higher likelihood of being inactive, a finding that have been reported earlier (Burton \& Turrell 2000; Martinez-Gonzalez 2001). Accumulation of non-healthy conditions is a probable explanation for this finding.

Our data showed marked differences between males and females on the prevalence of inactivity, regardless of the criteria used. In all of them, men were more likely to be considered active. In our view, a possible explanation for the gender difference in leisure-time practice is related to the reasons reported for being engaged in physical activity. In our study, enjoyment was the reason reported for almost half of men, against only $1 / 4$ of women. On the other hand, "because a physician recommended me to practice physical activity" was cited for more women than men. These contrasting findings may have important implication in terms of public health and may be explained by many factors, such as cultural and social ones. Although the instrument we used to estimate leisure-time physical activity (IPAQ) does not gather data about which activities are performed, it has been shown that Brazilian men practice more activities in group (soccer, volleyball, and basketball) than women, who practice more individualized activities (swimming, walking, and jogging) (Monteiro et al. 2003). This pattern is also observed among Brazilian adolescents (da Silva \& Malina 2000). In summary, these data indicate that while men practice physical activity because they enjoy it, women seem to practice it with the goal of either improvement of health or aesthete. Women also reported practicing physical activity because of a medical advice more frequently than men. The fact that women also visit a physician more regularly than men might explain this difference (Mendoza-Sassi \& Beria 2003). Thereby, health professionals must be aware of their potential to mediate healthy behavior, not only among sick individuals, but also in the population as a whole.

Because only leisure-time activities were investigated, one should realize that subjects with no activity in our study may have some degree of physical activity in other domains, such as occupation, housework or transportation. Studies on leisure-time activities alone are valuable for understanding variables associated with intentional physical activity practice, because level of activity at work, for example, does not depend on the will of the subject alone. 
In summary our data shall be used as a support by policy makers in order to plan interventions to increase the population level of leisure-time physical activity. Furthermore, interventions might focus on different aspects, depending on the gender targeted. At last, since inactivity is known to be mediated by an extended number of factors others than demographic (e.g. psychological, cognitive, behavioral attributes, social,

\section{Zusammenfassung}

Geschlechterbedingte Unterschiede bei körperlichen Aktivitäten in der Freizeit

Ziel: Die Beziehung zwischen Geschlecht und körperlichen Freizeitktivitäten in einer bevölkerungsbasierten Stichprobe von in Brasilien lebenden Erwachsenen zu untersuchen.

Methoden: Ein mehrstufiges Sampling von Haushalten wurde in Pelotas durchgeführt, einer mittelgrossen südbrasilianischen Stadt. Körperliche Freizeitaktivitäten wurden anhand der Langversion des Fragebogens zur Erhebung gesundheitsrelevanter körperlicher Aktivität (IPAC) gemessen. Daten zu potentiellen Prädiktoren des Verhaltens im Bereich der körperlichen Freizeitaktivitäten wurden mittels eines standardisierten Frage- environmental, and cultural) (Trost et al. 2002), a behavioral shift in the desired direction is dependent of an intervention tailoring all of these factors.

\section{Acknowledgements}

Coordenação de Aperfeiçoamento de Pessoal de Nível Superior (CAPES). bogens erhoben. Es wurden 1344 Männer und 1756 Frauen befragt. Verschiedene Definitionen körperlicher Aktivität von moderater bzw. starker Intensität kamen zur Anwendung.

Ergebnisse: Unabhängig der verwendeten Richtlinien waren Männer aktiver als Frauen. Der sozioökonomische Status war negativ assoziiert mit körperlichen Freizeitaktivitäten bei beiden Geschlechtern. Eine positive Dosis-Wirkungs-Beziehung zwischen Alter und Inaktivität konnte bei Männern festgestellt werden, jedoch nicht bei Frauen.

Schlussfolgerungen: Da Männer und Frauen ein unterschiedliches Mass an körperlicher Aktivität aufweisen und die Variablen, die mit körperlicher Betätigung assoziiert sind, zwischen den Geschlechtern nicht einheitlich sind, sollten Interventionen zur Förderung körperlicher Aktivität diese Unterschiede berücksichtigen.

\section{Résumé}

Pratique de l'activité physique durant les loisirs: différences entre les sexes

Objectifs: Etudier l'association entre le genre et la pratique de I'activité physique durant les loisirs dans un échantillon populationnel d'adultes vivant au Brésil. Etudier différentes variables qui pourraient être associées avec les niveaux d'activité physique.

Méthodes: Un échantillonnage en grappe des ménages a été effectué à Pelotas, un ville de taille moyenne au sud du Brésil. L'activité physique pratiquée durant les loisirs a été mesurée au moyen de la version longue du «Questionnaire International d'Activité Physique». Les variables prédictrices de la pratique de l'activité physique durant les loisirs ont été collectées au moyen d'un questionnaire standardisé. 1344 hommes et 1756 femmes ont été interviewés. Diverses définitions actuelles des niveaux d'activité physique recommandés (modérée/intense) ont été utilisées.

Résultats: Indépendamment des recommandations utilisées comme critères, les hommes étaient plus actifs que les femmes. Le niveau socio-économique était associé négativement avec la pratique d'une activité physique pendant les loisirs pour les deux sexes. Une dose-réponse positive entre l'âge et la sédentarité a été identifiée chez les hommes mais pas chez les femmes.

Conclusions: Les hommes et les femmes ont des niveaux de pratique de l'activité physique différents. Les variables associées à cette pratique varient également entre les sexes. Les interventions de promotion de l'activité physique devraient donc tenir compte de ces spécificités.

\section{References}

Abel T, Graf N, Niemann S (2001). Gender bias in the assessment of physical activity in population studies. Soz Praventiv Med 46: 268-72.
Barros MVG, Nahas MV (2000). Reprodutibilidade (teste-reteste) do Questionário Internacional de Atividade Física (QIAF-versão 6): um estudo piloto com adultos no Brasil. Rev Bras Ciênc e Mov 8: 23-6.
Bucksch J, Schlicht W (2006). Health-enhancing physical activity and the prevention of chronic diseases - an epidemiological review. Soz Praventiv Med 51: 281-301. 
Burton NW, Turrell G (2000). Occupation, hours worked, and leisure-time physical activity. Prev Med 31: 673-81.

Craig CL, Marshall AL, Sjostrom M et al. (2003). International physical activity questionnaire: 12country reliability and validity. Med Sci Sports Exerc 35: 1381-95.

da Silva RC, Malina RM (2000). [Level of physical activity in adolescents from Niteroi, Rio de Janeiro, Brazil]. Cad Saude Publica 16: 1091-7.

Domingues MR, Araujo CL, Gigante DP (2004). [Knowledge and perceptions of physical exercise in an adult urban population in Southern Brazil]. Cad Saude Publica 20: 204-15.

Evenson KR, Wilcox S, Pettinger M, Brunner R, King AC, McTiernan A (2002). Vigorous leisure activity through women's adult life: the Women's Health Initiative Observational Cohort Study. Am J Epidemiol 156: 945-53.

Gomes VB, Siqueira KS, Sichieri R (2001). [Physical activity in a probabilistic sample in the city of Rio de Janeiro]. Cad Saude Publica 17: 969-76.

Gomez LF, Mateus JC, Cabrera G (2004). Leisure-time physical activity among women in a neighbourhood in Bogota, Colombia: prevalence and socio-demographic correlates. Cad Saude Publica 20: 1103-9.

Hallal PC, Matsudo SM, Matsudo VKR, Araújo $T L$, Andrade DR, Bertoldi AD (2005). Physical activity in adults from two Brazilian areas: similarities and differences. Cad Saude Publica 21: 573-80.

Hallal PC, Siqueira FV (2004). Compliance with vigorous physical activity guidelines in Brazilian adults: prevalence and correlates. Journal of Physical Activity and Health 1: 389-97.
Hallal PC, Victora CG, Wells JC, Lima RC (2003). Physical inactivity: prevalence and associated variables in Brazilian adults. Med Sci Sports Exerc 35: 1894-900.

Hallal PC, Victora CG, Wells JCK, Lima RC, Valle NJ (2004). Comparison between short and full-length International Physical Activity Questionnaires (IPAQ). Journal of Physical Activity and Health 1: 227-34.

Marmot M (2000). Social determinants of health: from observation to policy. Med J Aust 172: $379-82$.

Martinez-Gonzalez MA, Varo JJ, Santos JL, De Irala J, Gibney M, Kearney J, Martinez JA (2001). Prevalence of physical activity during leisure time in the European Union. Med Sci Sports Exerc 33: 1142-6.

Mendoza-Sassi R, Beria JU (2003). Prevalence of having a regular doctor, associated factors, and the effect on health services utilization: a population-based study in Southern Brazil. Cad Saude Publica 19: 1257-66.

Ministério da Saúde (2002). Physical activity and life quality contribution in order to obtain a better health lifestyle. Rev Saúde Pública 36: 254-6.

Monteiro CA, Conde WL, Matsudo SM, Matsudo VR, Bonsenor IM, Lotufo PA (2003). A descriptive epidemiology of leisure-time physical activity in Brazil, 1996-1997. Rev Panam Salud Publica 14: 246-54.

Pardini R, Matsudo SMM, Araújo T, Matsudo $V K R$, Andrade E, Braggion G (2001). Validação do Questionário Internacional de Nível de Atividade Física (IPAQ-versão 6): estudo piloto em adultos jovens brasileiros. Rev Bras Ciên e Mov 9: 45-51.
Steptoe A, Wardle J, Cui W, Bellisle F, Zotti AM, Baranyai R, Sanderman $R$ (2002). Trends in smoking, diet, physical exercise, and attitudes toward health in European university students from 13 countries, 1990-2000. Prev Med 35: 97-104.

Trost SG, Owen N, Bauman AE, Sallis JF, Brown $W$ (2002). Correlates of adult's participation in physical activity: review and update. Med Sci Sports Exerc 34: 1996-2001.

U.S. Department of Health and Human Services (1996). Physical activity and health: A report of the Surgeon General. Atlanta, GA: U.S. Department of Health and Human Services, Center for Disease Control and Prevention, National Center for Chronic Disease Prevention and Health Promotion.

U.S. Department of Health and Human Services (2000). Healthy People 2010. Washington D.C.

Varo JJ, Martinez-Gonzalez MA, De Irala-Estevez J, Kearney J, Gibney M, Martinez JA (2003). Distribution and determinants of sedentary lifestyles in the European Union. Int J Epidemiol 32: $138-46$.

World Health Organization (2004). Global strategy on diet, physical activity and health: World Health Organization.

\author{
Address for correspondence: \\ Mario Renato Azevedo \\ Post-graduate Program in Epidemiology \\ Federal University of Pelotas, Brazil \\ Av. Duque de Caxias, 250 - 3rd floor \\ CEP: 96030-002 \\ Tel.: + 555332712442 \\ Fax: + 555332712645 \\ e-mail: marioazevedojr@terra.com.br
}

To access this journal online: http://www.birkhauser.ch/IJPH 